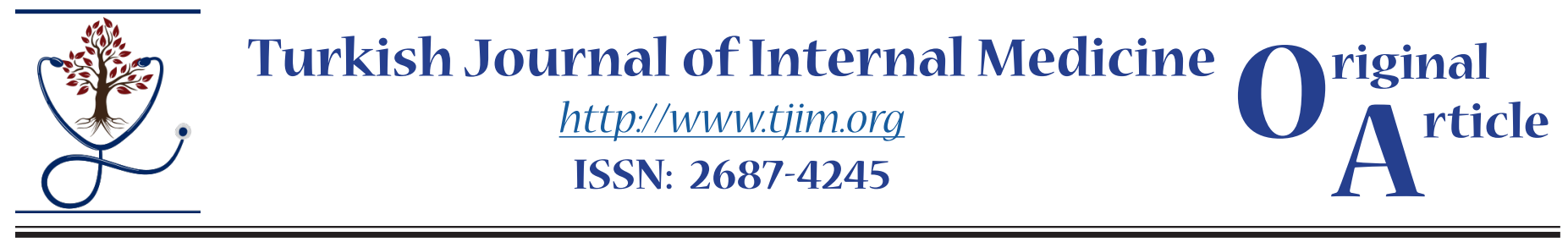

\title{
Effects of Cigarette Smoking on Total and Salivary Cortisol Levels
}

Gülşah Elbüken D,

Department of Endocrinology \& Metabolism, Tekirdağ Namık Kemal University, Tekirdağ, Turkey

\begin{abstract}
Introduction: Although there are some studies regarding the effects of cigarette smoking on serum total cortisol (TC) and salivary cortisol ( $\mathrm{SaC}$ ) levels, the results are still not conclusive. For this purpose, we aimed to determine the effects of cigarette smoking on $\mathrm{TC}$ and $\mathrm{SaC}$ levels in a small sample of healthy volunteers.

Methods: Twenty-five ( 12 females and 13 males) smokers with a mean age of $42.6 \pm 15$ years and 25 (12 females and 13 males) age- and gender-matched healthy non-smokers (mean age: $40.8 \pm 14.5$ years) were enrolled in the study. Hypothalamic-pituitary-adrenal (HPA) axis was evaluated by baseline TC and SaC levels, and $\mathrm{TC}$ and $\mathrm{SaC}$ responses to standard dose $(250 \mu \mathrm{g}) \mathrm{ACTH}$ stimulation test. TC and SaC levels were obtained under baseline and stimulated conditions.

Results: Although mean TC and SaC levels were higher in smokers versus non-smokers, a statistically significant difference was not found between the two groups.

Conclusion: TC and SaC levels were not statistically different between smokers and non-smokers. Further studies with a larger sample size are needed to draw definitive conclusions.
\end{abstract}

Keywords: Smoking, serum total cortisol, salivary cortisol, ACTH stimulation test

\section{Introduction}

Cortisol is a stress hormone which may be influenced by cigarette smoking. Cigarette smoking can interfere with steroid hormone release, binding, transport, storage, metabolism, and clearance, resulting in changes in circulating hormone concentrations. ${ }^{1,2}$ It is known that smoking is associated with moderately elevated cortisol levels. ${ }^{2}$ Several studies have reported the stimulating effects of acute doses of nicotine delivered by cigarette smoking on the hypothalamic-pituitary-adrenal (HPA) axis. ${ }^{2-}$ ${ }^{4}$ Nicotine has a stimulatory effect on HPA axis 
activity with increased plasma cortisol and urinary 17-hydroxycorticosteroid levels detected following cigarette smoking. ${ }^{2}$ Nicotine probably stimulates hypothalamic cholinergic receptors, leading to a release of corticotropin-releasing hormone $(\mathrm{CRH})$. Nicotine also stimulates adrenocorticotropic hormone $(\mathrm{ACTH})$ secretion from the anterior pituitary with a subsequent cortisol release from the adrenal cortex. Additionally, nicotine induces vasopressin secretion which can lead to ACTH release. ${ }^{4}$ It is also known that total cortisol (TC) levels increase within the first 20 minutes after cigarette smoking. ${ }^{5}$ On the other hand, acute tobacco abstinence was shown to cause a reduction in TC. ${ }^{6}$

Cortisol levels can be measured in plasma, urine, and saliva. Salivary cortisol $(\mathrm{SaC})$ directly diffuses along the capillaries to target tissues and it is a biomarker of serum free cortisol (FC) level. Sampling of saliva is easy and painless. SaC, as a surrogate biomarker of $\mathrm{FC}$ has been increasingly used in scientific studies. ${ }^{7-10}$ There are controversial data in literature regarding the effect of cigarette smoking on $\mathrm{SaC}$. In one study, $\mathrm{SaC}$ levels were increased in current smokers compared with nonsmokers. ${ }^{11}$ Cessation of cigarette smoking results in a reduction of SaC levels. ${ }^{12}$ In a study by Wong et al., SaC levels were significantly lower during the abstinent session versus the non-abstinent session in the same population. ${ }^{13}$ However, in some other studies it was concluded that $\mathrm{SaC}$ levels were not affected by cigarette smoking. ${ }^{14-16}$ As previously mentioned, evidence for an association of smoking with $\mathrm{SaC}$ are mixed. For this purpose, we aimed to investigate $\mathrm{SaC}$ levels of cigarette smokers and non-smokers in a population of healthy volunteers.

\section{Methods}

Twenty-five healthy smokers ( 12 females and 13 males) with a mean age of $42.6 \pm 15$ years, and 25 age- and sex-matched (12 females and 13 males) healthy non-smoker (mean age: $40.8 \pm 14.5$ years) controls were enrolled in the study. The duration of cigarette smoking was estimated by pack-years (number of packs of cigarettes smoked per day $\mathrm{x}$ years smoked per person). This study was part of another study investigating the HPA function of healthy people at our hospital. The study was approved by the Local Ethics Committee and informed consent was obtained from all volunteers. Exclusion criteria included a diagnosis of diabetes mellitus, malignancy, history of corticosteroid exposure, oral contraceptive use, and also the presence of any condition that could affect functioning of the HPA axis.

ACTH stimulation tests: Tests were performed between 08:00-09:00 a.m., after an overnight fast. Blood and saliva samples for $\mathrm{TC}$ and $\mathrm{SaC}$ were obtained before and at 30, 60, 90 minutes after administration of $250 \mu \mathrm{g}$ synthetic ACTH. ${ }^{17}$ Samples were centrifuged, aliquoted and stored at $-80{ }^{\circ} \mathrm{C}$ until analysis.

Salivary samples: Sixty minutes before the test, individuals were not allowed to smoke, eat, drink liquids or brush their teeth. Saliva samples were collected by using oral swabs (Salimetrics $\left.{ }^{\circledR}\right) .{ }^{18}$ Salivary cortisol was measured using a commercially available high-sensitivity enzyme immunoassay (EI) kit (Salimetrics ${ }^{\circledR}$ Inc, State College, PA, USA) according to the manufacturer's instructions. ${ }^{9}$

Serum TC: Serum TC levels were measured by radioimmunoassay (RIA) method (Immunotech; Prague, Czech Republic).

\section{Statistical analyses}

All statistical analyses were conducted using the Statistical Package for Social Sciences (SPSS for Windows, version 15; Chicago; IL). Since the data were distributed homogenously, statistical analyses were performed by parametric tests. The results were presented as mean and standard deviation (SD). Comparisons between two groups of data were done by paired t-test. Statistical significance was set at a $\mathrm{p}$-value less than 0.05 .

\section{Results}

Demographic and smoking status of the study subjects are shown in Table 1. Mean duration of smoking was 14 \pm 14 (median: 9, min: 1, max: 45) years for the study sample and $13.3 \pm 16$ (median:7, min: 1, max: 45) and 15.5 \pm 10.4 (median: 15, min: 25, max: 30) years respectively for females and males. Baseline, peak and delta hormone levels of the smoker and non-smoker groups are summarized in Table 2.

Although mean TC and SaC levels at baseline and 30, 60 and 90 minutes after ACTH stimulation 
Table 1: Demographic characteristics of the subjects.

\begin{tabular}{llc}
\hline Group & \multicolumn{2}{c}{ Age (years) } \\
\hline Smokers $(\mathrm{n}=\mathbf{2 5})$ & $44.8 \pm 15.5(\mathrm{~F}, \mathrm{n}=12)$ & $42.6 \pm 15$ \\
& $40.5 \pm 15(\mathrm{M}, \mathrm{n}=13)$ & \\
Non- smokers $(\mathrm{n}=\mathbf{2 5})$ & $44.5 \pm 14.4(\mathrm{~F}, \mathrm{n}=12)$ & $40.8 \pm 14.5$ \\
& $36.8 \pm 14(\mathrm{M}, \mathrm{n}=13)$ & 0.89 \\
\hline
\end{tabular}

Table 2: Baseline, peak and delta hormone levels of the subjects during $250 \mu \mathrm{g} \mathrm{ACTH}$ stimulation test.

\begin{tabular}{llcccl}
\hline & $\begin{array}{c}\text { Baseline } \\
\text { (Mean, SD) }\end{array}$ & $\begin{array}{c}\text { Peak } \\
\text { (Mean, SD) }\end{array}$ & $\begin{array}{c}\text { Delta } \\
\text { (Mean, SD) }\end{array}$ & p value \\
\hline TC & Smokers & $11.8 \pm 7$ & $34.8 \pm 11.4$ & $23 \pm 12.4$ & $<0.01$ \\
$(\boldsymbol{\mu g} / \mathbf{d L})$ & Non-smokers & $8.9 \pm 4.6$ & $31.2 \pm 9.3$ & $22.3 \pm 11.8$ & $<0.01$ \\
& $\boldsymbol{p}$ value & 0.09 & 0.22 & 0.82 & \\
\cline { 2 - 6 } $\mathrm{SaC}$ & Smokers & $0.53 \pm 0.54$ & $2.55 \pm 1$ & $2 \pm 0.98$ & $<0.01$ \\
$(\boldsymbol{\mu g} / \mathrm{dL})$ & Non-smokers & $0.51 \pm 0.40$ & $2.34 \pm 0.78$ & $1.81 \pm 0.73$ & $<0.01$ \\
& $\boldsymbol{p}$ value & 0.89 & 0.43 & 0.35 & \\
\hline
\end{tabular}

$\mathrm{TC}=$ Total cortisol, $\mathrm{SaC}=$ Salivary Cortisol

Mean Serum Total Cortisol Levels During $250 \mu \mathrm{g}$ ACTH Stimulation Test

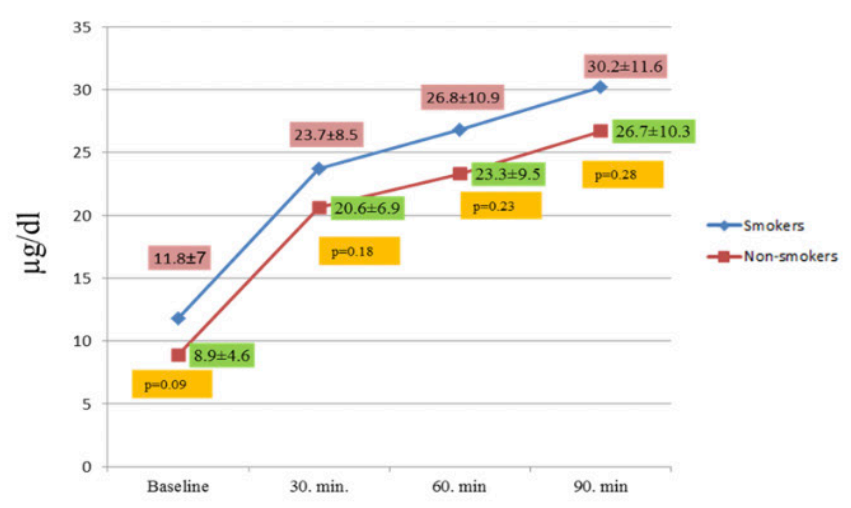

Figure 1a. TC levels at baseline and 30,60 and 90 minutes after ACTH stimulation test
Mean Salivary Cortisol Levels During $250 \mu \mathrm{g}$ ACTH Stimulation Test

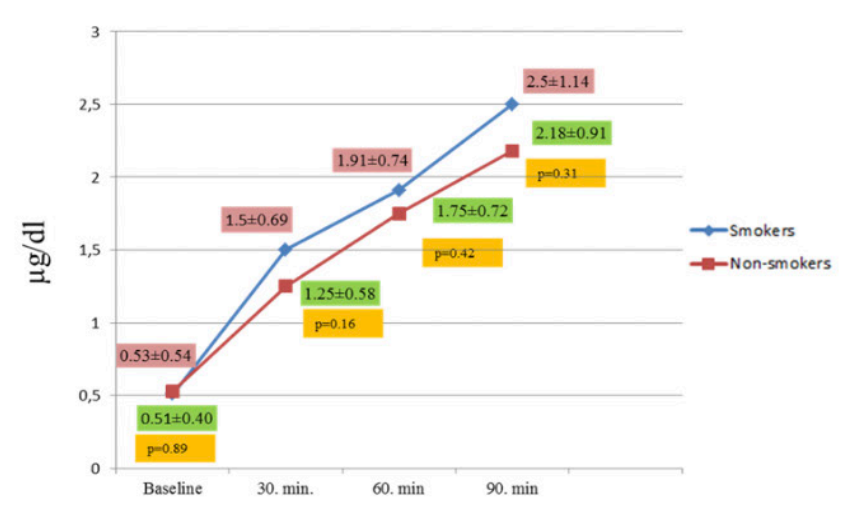

Figure 1b. SaC levels at baseline and 30,60 and 90 minutes after ACTH stimulation test test were higher among smokers, a statistically significant difference was not found between the two groups (Figures 1a and 1b). As shown in Figure 2, baseline and stimulated $\mathrm{SaC}$ levels were also similar among males, females and overall.

\section{Discussion}

In any investigation on the effects of smoking on cortisol, consideration should be given to the type of method used for cortisol measurement (TC, FC or SaC) while interpreting the results. 


\section{Salivary Cortisol Levels of The Subjects}

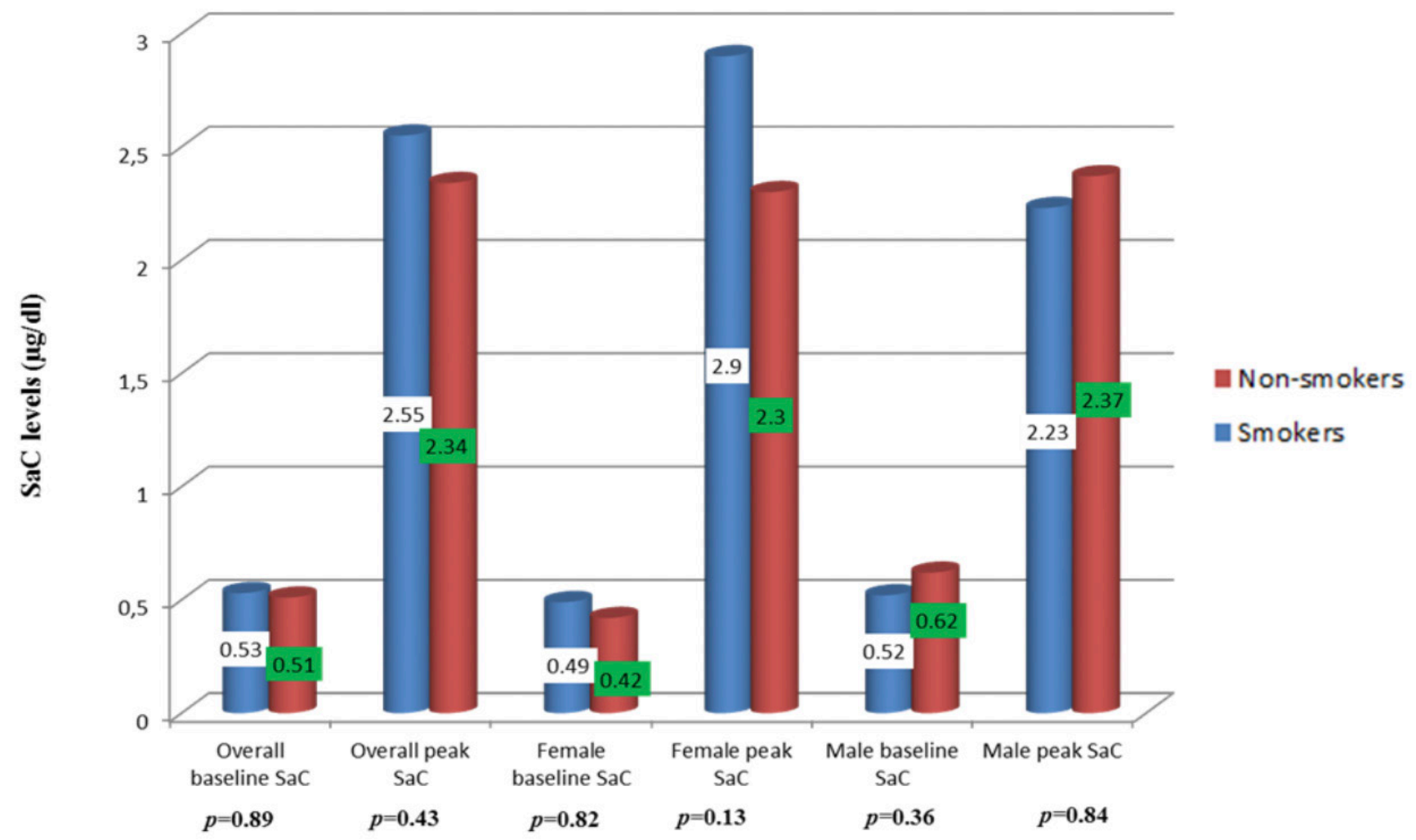

Figure 2: Salivary cortisol levels of the subjects overall and in female and male groups.

This is because it is known that the biologically active fraction of cortisol is FC and it should be the primary fraction to be measured since it is not affected by cortisol-binding proteins. However, FC measurement is a cumbersome and timeconsuming method that is dependent on laboratory and technician. However, when $\mathrm{SaC}$ is directly measured using the EI method, it is not affected by cortisol-binding proteins or any factors that could have an impact on these proteins.

In our study, $\mathrm{TC}$ and $\mathrm{SaC}$ levels of the subjects were not statistically different between smoking and non-smoking groups. Studies comparing smokers and non-smokers using TC showed that TC was generally higher among smokers. ${ }^{2,5,11}$ However, Handa et al. ${ }^{19}$ found lower morning TC values in a group of middle-aged male smokers.19 In our study, baseline and stimulated TC values did not differ between sexes. We also found that $\mathrm{SaC}$ levels were not different between smokers and non-smokers in the present study. Considering that $\mathrm{SaC}$ reflects biologically active $\mathrm{FC}$, we may suggest that smoking does not have any effect on FC levels. Consistent with our findings, in their study Yeh and Barbieri ${ }^{20}$ showed that urinary cortisol levels which reflected FC were not different between 10 smokers and 15 non-smokers. Contrastingly, Kirschbaum et al. reported higher $\mathrm{SaC}$ levels in smokers than in non-smokers in two studies. ${ }^{21,22}$ In a new study published in 2019, examining cortisol secretion and sleep continuity in smokers and non-smokers, a marked difference was observed between $\mathrm{SaC}$ values of 38 regular smokers and 39 non-smokers $(0.73 \pm 0.58 \mu \mathrm{g} / \mathrm{dL}$ versus $0.47 \pm 0.26$ $\mu \mathrm{g} / \mathrm{dL}$, respectively). ${ }^{23}$ In the present study, we did not find any difference between $\mathrm{SaClevels}$ between smokers and non-smokers at baseline and following ACTH stimulation. This finding suggests that several ingredients found in cigarettes including nicotine do not have a local effect on SaC. Also, it suggests that smoking does not have an additional impact on the HPA axis. In conclusion, we believe that it might be more appropriate to utilize $\mathrm{SaC}$ to assess FC in future studies that examine the HPA axis in relation to smoking status.

\section{Conclusion}

Although there were only 25 smokers in our study, we found that cigarette smoking did not 
have an effect on TC and SaC levels. Further studies with a larger sample size are needed to draw definitive conclusions.

\section{Conflict of interest}

The authors declared that there are no potential conflicts of interest with respect to the research, authorship, and/or publication of this article.

Note: This study was partly reported as a poster presentation at the European Congress of Endocrinology (ECE) held between May 16-20, 2015 in Dublin, Republic of Ireland.

\section{References}

1. Muranaka H, Higashi E, Itani S, Shimizu Y. Evaluation of nicotine, cotinine, thiocyanate, carboxyhemoglobin, and expired carbon monoxide as biochemical tobacco smoke uptake parameters. Int Arch Occup Environ Health. 1988;60(1):37-41. doi: 10.1007/BF00409377.

2. Wilkins JN, Carlson HE, Van Vunakis H, Hill MA, Gritz E, Jarvik ME. Nicotine from cigarette smoking increases circulating levels of cortisol, growth hormone, and prolactin in male chronic smokers. Psychopharmacology (Berl). 1982;78(4):305-8. doi: 10.1007/BF00433730.

3. Pomerleau OF, Fertig JB, Seyler LE, Jaffe J. Neuroendocrine reactivity to nicotine in smokers. Psychopharmacology (Berl). 1983;81(1):61-7. doi: 10.1007/BF00439275.

4. Kirschbaum C, Wüst S, Faig HG, Hellhammer DH. Heritability of cortisol responses to human corticotropinreleasing hormone, ergometry, and psychological stress in humans. J Clin Endocrinol Metab. 1992 Dec;75(6):1526-30. doi: 10.1210/jcem.75.6.1464659.

5. Mendelson JH, Sholar MB, Goletiani N, Siegel AJ, Mello NK. Effects of low- and high-nicotine cigarette smoking on mood states and the HPA axis in men. Neuropsychopharmacology. 2005 Sep;30(9):1751-63. doi: 10.1038/sj.npp.1300753.

6. Koob GF, Le Moal M. Drug addiction, dysregulation of reward, and allostasis. Neuropsychopharmacology. 2001 Feb;24(2):97-129. doi: 10.1016/S0893-133X(00)00195-0.

7. Arafah BM, Nishiyama FJ, Tlaygeh H, Hejal R. Measurement of salivary cortisol concentration in the assessment of adrenal function in critically ill subjects: a surrogate marker of the circulating free cortisol. J Clin Endocrinol Metab. 2007 Aug;92(8):2965-71. doi: 10.1210/jc.2007-0181.

8. Lo MS, Ng ML, Azmy BS, Khalid BA. Clinical applications of salivary cortisol measurements. Singapore Med J. 1992 Apr;33(2):170-3.

9. Gozansky WS, Lynn JS, Laudenslager ML, Kohrt WM. Salivary cortisol determined by enzyme immunoassay is preferable to serum total cortisol for assessment of dynamic hypothalamic--pituitary--adrenal axis activity. Clin Endocrinol(Oxf). 2005 Sep;63(3):336-41. doi: 10.1111/j.1365- 2265.2005.02349.x

10. Marcus-Perlman Y, Tordjman K, Greenman Y, Limor R, Shenkerman G, Osher E, Stern N. Low-dose ACTH (1 microg) salivary test: a potential alternative to the classical blood test. Clin Endocrinol (Oxf). 2006 Feb;64(2):215-8. doi: 10.1111/j.1365-2265.2006.02451.x.

11. Badrick E, Kirschbaum C, Kumari M. The relationship between smoking status and cortisol secretion. J Clin Endocrinol Metab. 2007 Mar;92(3):819-24. doi: 10.1210/ jc.2006-2155.

12. Frederick SL, Reus VI, Ginsberg D, Hall SM, Munoz RF, Ellman G. Cortisol and response to dexamethasone as predictors of withdrawal distress and abstinence success in smokers. Biol Psychiatry. 1998 Apr 1;43(7):525-30. doi: 10.1016/S0006-3223(97)00423-X.

13. Wong JA, Pickworth WB, Waters AJ, al'Absi M, Leventhal AM. Cortisol levels decrease after acute tobacco abstinence in regular smokers. Hum Psychopharmacol. 2014 Mar;29(2):152-62. doi: 10.1002/hup.2382.

14. Hansen AM, Garde AH, Christensen JM, Eller NH, Netterstrøm B. Evaluation of a radioimmunoassay and establishment of a reference interval for salivary cortisol in healthy subjects in Denmark. Scand J Clin Lab Invest. 2003;63(4):303-10. doi: 10.1080/00365510310001942.

15. Wüst S, Wolf J, Hellhammer DH, Federenko I, Schommer $\mathrm{N}$, Kirschbaum C. The cortisol awakening response - normal values and confounds. Noise Health. 2000;2(7):79-88.

16. Kudielka BM, Kirschbaum C. Awakening cortisol responses are influenced by health status and awakening time but not by menstrual cycle phase. Psychoneuroendocrinology. 2003 Jan;28(1):35-47. doi: 10.1016/s0306-4530(02)00008-2.

17. Karaca Z, Lale A, Tanriverdi F, Kula M, Unluhizarci K, Kelestimur F. The comparison of low and standard dose $\mathrm{ACTH}$ and glucagon stimulation tests in the evaluation of hypothalamo-pituitary-adrenal axis in healthy adults. Pituitary. 2011 Jun;14(2):134-40. doi: 10.1007/s11102-0100270-3.

18. Topkas E, Keith P, Dimeski G, Cooper-White J, Punyadeera C. Evaluation of saliva collection devices for the analysis of proteins. Clin Chim Acta. 2012 Jul 11;413(13-14):1066-70. doi: 10.1016/j.cca.2012.02.020.

19. Handa K, Kono S, Ishii H, Shinchi K, Imanishi K, Arakawa $\mathrm{K}$. Relationship of alcohol consumption and smoking to plasma cortisol and blood pressure. J Hum Hypertens. 1994 Dec;8(12):891-4.

20. Yeh J, Barbieri RL. Twenty-four-hour urinary-free cortisol in premenopausal cigarette smokers and nonsmokers. Fertil Steril. 1989 Dec;52(6):1067-9. doi: 10.1016/s00150282(16)53177-x.

21. Kirschbaum C, Wüst S, Strasburger CJ. 'Normal' cigarette smoking increases free cortisol in habitual smokers. Life Sci. 1992;50(6):435-42. doi: 10.1016/0024-3205(92)90378-3.

22. Kirschbaum C, Scherer G, Strasburger CJ. Pituitary and adrenal hormone responses to pharmacological, physical, and psychological stimulation in habitual smokers and nonsmokers. Clin Investig. 1994 Oct;72(10):804-10. doi: 10.1007/BF00180552.

23. Cohen A, Colodner R, Masalha R, Haimov I. The Relationship Between Tobacco Smoking, Cortisol Secretion, and Sleep Continuity. Subst Use Misuse. 2019;54(10):170514. doi: 10.1080/10826084.2019.1608250. 